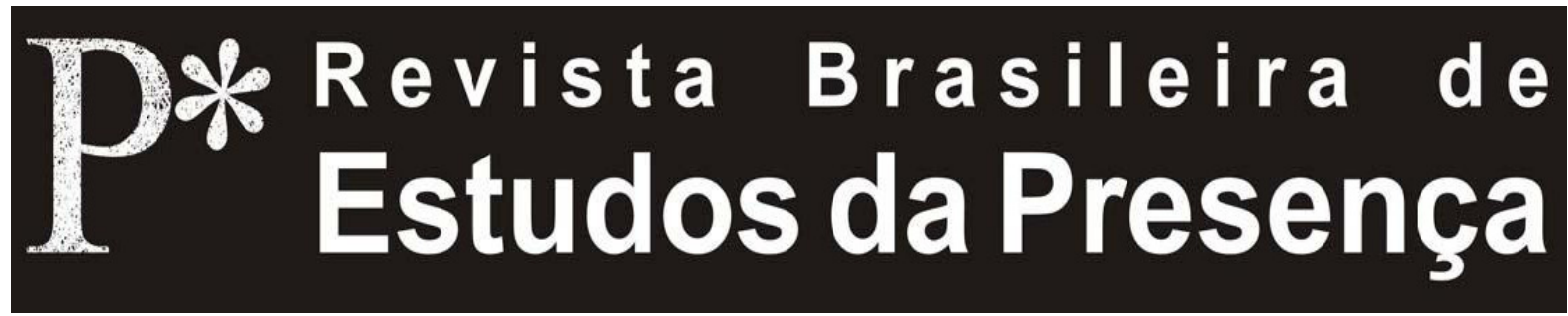

DOI - http://dx.doi.org/10.1590/2237-266036374

ISSN 2237-2660

\title{
Por uma Genética Teatral: premissas e desafios
}

\author{
Almuth Grésillon \\ Marie-Madeleine Mervant-Roux \\ Centre National de la Recherche Scientifique - CNRS, Paris, França
}

Dominique Budor

Université Paris 3 Sorbonne Nouvelle - Paris, França

RESUMO - Por uma Genética Teatral: premissas e desafios ${ }^{1}$ - É possível aplicar ao teatro o método genético, conhecido e utilizado no domínio da literatura? A obra teatral é um conjunto heterogêneo de dados textuais e cênicos, uma entidade efêmera e fugidia, pois toda encenação, mas também cada apresentação, engendra necessariamente novas modificaçóes: cortes no texto; variaçóes nos movimentos dos corpos; os timbres das vozes; as luzes; o ritmo do acontecimento, etc. Como, nessas condiçóes, retraçar a gênese da obra, entre objetos de diversos tipos e de múltiplos acabamentos?

Palavras-chave: Genética Teatral. Teatro. Texto. Performance. Inacabamento.

ABSTRACT - For a Theatrical Genetics: assumptions and challenges - Is it possible to apply to theatre the genetic method, known and used in the field of literature? A theatrical work is a heterogeneous set of textual and scenic data, an ephemeral and fleeting entity, because every staging - but also every presentation - necessarily produces new modifications: text cuts; variations in body movements; different voice timbres; lighting; the pace of the event, etc. In these conditions, how is it possible to retrace the genesis of the work, among objects of several kinds and with multiple finishes?

Keywords: Theatrical Genetics. Theatre. Text. Performance. Unfinishedness.

RÉSUMÉ - Pour une Génétique Théâtrale: prémisses et enjeux - Est-il possible d'appliquer au théâtre la méthode génétique, connue pour avoir fait ses preuves en littérature? L'œuvre théâtrale est un ensemble hétérogène de données textuelles et scéniques, une entité éphémère et fugitive, puisque toute mise en scène, mais aussi chaque représentation engendre nécessairement de nouvelles modifications: coupures dans le texte, variantes dans les mouvements des corps, les timbres des voix, les lumières, le rythme de l'événement, etc. Comment, dans ces conditions, retracer la genèse de l'œuvre, entre objets de diverses sortes et multiples achèvements?

Mots-clés: Génétique Théâtrale. Théâtre. Texte. Performance. Inachèvement. 
Uma confusão dos sons, das coisas e dos seres. Uma espécie de rascunho interminável em que se busca a obra, tomando emprestado todas as liberdades do dia e da noite (Jean Vilar, 1975, p. $455^{2}$ ).

Interdisciplinaridade? Seria preciso dispor de outra palavra, mais leve e mais concreta ao mesmo tempo, para traduzir o modo de colaboração que marcou a preparaçáo desta obra ${ }^{3}$ e que lhe dá seu caráter teórico e metodológico. O entrelaçamento da crítica genética, das pesquisas sobre o teatro (aquelas que pensam a arte da cena nas suas relaçóes com outras artes) e dos estudos literários (aqueles que pensam o texto em seu devir) tem por efeito direcionar o olhar ao conjunto das gêneses teatrais, sem separar as diversas práticas realizadas, escritas, corporais ou cenográficas. Esta obra reúne arquivos, que cobrem o período entre o início do século XIX e os primeiros anos do século XXI. Eles contêm, conforme cada caso, manuscritos e diários de escritores, esboços de cenários, livros de diretores, vestígios de ensaios. Todos foram constituídos e estudados em uma perspectiva geral largamente aberta, fora de classificaçóes acadêmicas inspiradas pelo binômio historicamente datado do Texto e da Cena ${ }^{4}$. Dramática ou cênica, a atenção sobre a obra estudada estava regularmente voltada para o que se encenava nas zonas fronteiriças, nos cruzamentos ou deslocamentos inesperados de gestos e de decisóes, de uma área a outra. Essa observação geral se enriqueceu por um tipo de efeito de lupa no momento frequentemente entendido como fundador da teatralidade: o nascimento da encenação no fim do século XIX. Uma vez que esse momento é ricamente representado nesta obra, é possível avaliar melhor sua importância. Se essa invenção parece ter tido fortes efeitos sobre as gêneses teatrais - ela transformou a própria concepção do espetáculo dramático e reorganizou as relaçóes entre todos os participantes -, a ideia largamente difundida, segundo a qual os diretores teriam retirados dos autores o primeiro lugar na criação teatral, está longe de ser verificada. O esquema tradicional, segundo o qual, em matéria de teatro, o textual precede o cênico, não resulta, no entanto, confortável. Esta obra mostra as declinaçóes variadas e evolutivas de uma interação permanente e provavelmente estrutural - ao menos no Ocidente - entre texto e encenação. Interação cuja fonte pode-se encontrar no dispositivo genérico do teatro: a) um certo espaço distinto - materialmente ou por simples convenção tácita - do espaço social ordinário; b) um ator portador de texto que não é um simples contador, mas que se inscreve ele 
mesmo no espaço fictício; c) uma ação dramatizada, que se exprime ou não no diálogo encenado; d) um espectador, que se distingue do simples transeunte e aceita o pacto ficcional (Konigson, 2001, p. 32-34) ${ }^{5}$. Nessa perspectiva, a distinção entre teatro contemporâneo e teatro não contemporâneo se vê largamente relativizada. Sem negar sua validade, esta obra convida a dissociar a transformaçáo propriamente artística do trabalho teatral daquilo que está ligado à evolução dos modos de arquivamento (o desenvolvimento da encenação coincidiu com a invenção das máquinas de registrar: o aparelho fotográfico e a câmera) ${ }^{6}$. O verdadeiro elemento permanente não é o texto, é o movimento entre o escrito e o gesto, entre o gesto e o escrito, antes, durante, depois da apresentação. A circulação contínua das funções de escritor, leitor, ouvinte, observador, experimentador, durante os ensaios e a necessidade de fixar, descrever e contar o evento teatral, é testemunhada com intensidade não apenas pelos escritores e pelos diretores, mas também pelos atores, pelos iluminadores, pelos sonoplastas e pelos cenógrafos. Eles produzem e frequentemente detêm os registros escritos de seu trabalho. Sabe-se o quanto os criadores podem reinventar o passado, esquecer, acreditar em seus esquecimentos, mas, eles contribuem de modo insubstituível para decifrar e completar esses vestígios, para prevenir as leituras errôneas.

Esta obra retém essa lição e a traduz em sua organização. As hipóteses dos pesquisadores, baseadas na materialidade dos arquivos, respondem aos depoimentos dos artistas entrevistados sobre suas próprias práticas.

Ao considerar, sem hierarquizar a priori, os vestígios das diversas práticas, dando muita atenção aos contextos estéticos, socioculturais, políticos nos quais elas se inscrevem (um empreendimento teatral, mesmo o mais confidencial, é um evento social), os pesquisadores encontram procedimentos e questionamentos que são, desde muito tempo, os dos artistas: como anotar e transmitir tais processos de criação ao mesmo tempo íntimos e públicos? Como conservar práticas que implicam e engendram objetos ou efeitos materialmente táo diferentes? Como memorizar uma arte tão efêmera?

\section{Uma Larga Paisagem Interdisciplinar}

\section{A Abordagem Genética}

Denominada também genética textual, a crítica genética, herdeira paradoxal do estruturalismo do qual ela recusava a fixidez 
formalista e a definição do texto como entidade autossuficiente, constituiu nos anos 1970 uma nova aventura intelectual no campo da literatura.

Seu objeto: os manuscritos literários, na medida em que comportam o vestígio de uma dinâmica, a do texto em devir. Seu método: o desvelamento do corpo e do curso da escrita acompanhada da construção de uma série de hipóteses sobre as operaçôes escriturais. Seu objetivo: a literatura como um fazer, como atividade, como movimento (Grésillon, 1994, p. 7)

Os geneticistas coletam e tornam legíveis os documentos de arquivos, identificam as operaçóes sistemáticas da escritura, "escrever, acrescentar, suprimir, substituir, permutar" (Grésillon, 1994, p. $7)^{8}$, constituem um dossiê genético válido. Foi submetendo-se a esse protocolo que eles se deram conta de que certo número de noçóes da crítica literária tradicional eram necessárias para uma redefinição: texto, obra, autor, intertextualidade.

Desde o fim dos anos 1980, o objeto da crítica genética se diversificou: ela se interessa pela arquitetura, pelas escritas científicas, pelas artes plásticas, pelo cinema? . Seu método se tornou ao mesmo tempo flexível e preciso. Sem abandonar a base teórica inicial, ela foi levada a adaptar suas ferramentas a esses novos campos da criação. Seu objetivo consolidou-se ao longo de trabalhos e debates que esses campos suscitaram entre os próprios geneticistas (Contat; Ferrer, 1998). Ela está também explicitada, em resposta direta ou indireta às interrogaçóes e críticas advindas de diversos horizontes: filologia, hermenêutica, história, sociologia (Hay, 1994) ${ }^{10}$. Contra as teorias do talento e o culto ao mistério da criaçáo, trata-se de descobrir as etapas do trabalho. Contra a teoria da obra acabada, trata-se de mostrar e demonstrar que o estado último é ao mesmo tempo muito mais instável, mais surpreendente e mais complexo que aquilo que os modos de análise anteriores sugeriam. O conhecimento dos esboços e das pistas não seguidas enriquece notadamente a sua leitura. Como assinalou Gérard Gennette (1989) ${ }^{11}$, para a literatura todas as materialidades a estudar se apresentam consideravelmente ampliadas.

Os intensos debates suscitados pela genética textual no campo literário fundavam-se na recusa de levar em consideração os rascunhos por si mesmos. Essa rejeição não diz respeito aos estudos teatrais, disciplina ainda recente ${ }^{12}$, em que a dificuldade de captar realizaçóes cênicas não captáveis por natureza conduziu a utilizar os vestígios dos ensaios nos quais elas poderiam ser acessadas. Logo, as 
reservas dos especialistas de teatro não se faziam em relaçáo ao exame dos processos de trabalho, que se praticava correntemente. Elas traduziam provavelmente uma reação a algumas partes do modelo teórico e metodológico da crítica genética: ela privilegiava o texto, ao passo que o fazer teatral acabava de tornar-se autônomo em relação às abordagens literárias do teatro; esse fazer manifestava um interesse apaixonado pelo devir, quando um dos problemas maiores dos analistas da cena era conseguir fixar as realizaçóes de uma arte performativa. Essa proximidade complexa entre duas disciplinas ainda em gestação esclarece, ao mesmo tempo, as hesitaçóes iniciais e o fato de que sejam organizadas, ao longo dos anos, certo número de trocas e colaboraçóes.

\section{Uma Longa Pré-História: os estudos de gênese}

Existiram em meio às pesquisas teatrais, ao menos desde os anos 1930 , práticas que prefiguravam a abordagem genética. A primeira edição crítica de um registro de encenação ${ }^{13}$, foi realizada em 1938 por uma atriz, Marie-Antoinette Allevy (dita Akakia-Viala), responsável com os Autant-Lara pelo Laboratório Arte e Ação e autora de uma tese sobre a encenaçáo no século XIX. No mesmo período, outras pessoas se empenharam em observar e reconstituir os modos de composição das obras dramáticas ${ }^{14}$.

O acompanhamento metódico do processo de criação do espetáculo aparece nos anos 1960, paralelamente ao estudo dos estratos de escrita pelos geneticistas. Ele não tem sempre a mesma função. Tomemos o exemplo da coleçáo histórica das Voies de la création théâtrale (dita também VCT). Que o objeto da pesquisa seja uma obra escrita ou uma encenação, convém distinguir - mesmo se na prática eles se encontram misturadas ${ }^{15}$ - dois casos distintos. Em um, o pesquisador faz a genética avant la lettre: assim, Bernard Dort (1972) propóe uma análise estrita das versôes sucessivas do texto de Galileu de Brecht ${ }^{16}$. No outro, o pesquisador se interessa pela gênese, ele pode até mesmo utilizar o vocabulário genético, mas seu objetivo permanece intacto: expor o que o conduziu à obra.

\section{Várias Constelaçôes de Pesquisas}

O período que viu os primeiros cruzamentos entre o método genético e o teatro (os anos 1980-1990) se assemelha a uma nebulosa. Trabalhos nascem e se desenvolvem, sem relação uns com os outros. 
Os primeiros pesquisadores em Estudos Teatrais a voltar a atenção ao procedimento genético não o fizeram de modo articulado, nem pelas mesmas razóes. Alguns, tendo observado o método de análise textual, viram nele o meio de abordar a escrita dramática em uma perspectiva dinâmica e pragmática, em consonância com a arte do teatro ${ }^{17}$. Outros foram sensíveis à materialidade dos arquivos e compreenderam como $o$ texto, tornado um objeto, um instrumento de trabalho marcado pelos ensaios, podia ser reintegrado no campo das artes do espetáculo, procedimento então excepcional, haja vista a clivagem estrita entre territórios universitários (Mervant-Roux, 2000) ${ }^{18}$. Outros retiveram, enfim, os princípios genéticos em sua generalidade, e conceberam sua adaptaçáo ao estudo do trabalho teatral propriamente dito, o qual não inclui, do seu ponto de vista, a gênese do texto. É o caso de Josette Féral, cujo interesse não foi despertado pelas primeiras aplicaçóes do método em obras dramáticas, mas pelo livro Éléments de Critique Génétique (Grésillon, 1994). Esses elementos teóricos pareciam poder ajudar a responder à pergunta que era entáo a sua: como estudar a performance cênica sem passar pela análise de espetáculo ${ }^{19}$ tal como ela era praticada, fazendo deste um objeto morto? Ao lembrar que o corte estrito estabelecido entre o processo de criação e a apresentação é artificial, que as pessoas de teatro não admitem essa ideia, que o próprio espectador sente confusamente toda uma vida por de trás do que ele vê, Féral encontra na abordagem genética uma fonte de inspiração. É o espirito da genética que ela retém. O método lhe parece reservado aos manuscritos literários, ou eventualmente aos textos de teatro, objetos que não concernem, na sua perspectiva parcial, à abordagem do teatro vivo (Féral, 1998) ${ }^{20}$.

Paralelamente a essas iniciativas heterogêneas, um movimento sem relaçáo com elas se inicia dentro do campo genético: alguns pesquisadores começam a ver no teatro um objeto teoricamente apaixonante, bastante próximo de seus objetos de predileçáo (eles desejam acrescentar o drama na poesia e na prosa), e ao mesmo tempo surpreendente, desconhecido, estranho, tendo em vista a dimensão física da performance. Os primeiros estudos genéticos feitos sobre obras dramáticas contemporâneas como as de Claudel e Brecht ${ }^{21}$, não podiam conduzir os pesquisadores à beira do palco. Uma verdadeira aventura científica começava, uma vez que a etapa seguinte consistiria em observar um processo diferentemente complexo, colocando em jogo não apenas corpos e vozes, mas um espaço, sons, luzes, a captar 
uma produção efêmera, recriada diferentemente em cada apresentação, e isso sem abandonar a dimensão textual da gênese.

\section{Elementos Catalisadores}

Vários fenômenos favoreceram o desenvolvimento de uma abordagem propriamente genética da criação teatral.

O mais importante é, provavelmente, a transformação dessa mesma criação nos anos 1960. Para certo número de artistas e de grupos (como Grotowski, Barba, o Living Theatre, o Open Theatre), náo se trata mais necessariamente de encenar uma obra dramática, no sentido usual do termo. Se eles se utilizam de materiais textuais durante a preparaçáo de seus espetáculos e lhes conferem uma grande importância, esses adquirem novas funçôes, modificáveis, dentro de um trabalho teatral que progride frequentemente por meio de improvisaçóes: explora-se um tema, criam-se efeitos expressivos a partir de impulsóes individuais. São essas sequências de pesquisa coletiva que devem ser observadas doravante, o que implica uma verdadeira renovação teórica e metodológica. O texto que abre o primeiro volume das Voies de la Création Théatrale, assinado por Jean Jacquot, esclarece notadamente esse momento. Ao recusar a "redução do estudo do teatro a um estudo do gênero literário" (Jacquot, 1970, p. 7-17) 22, a equipe do CNRS ${ }^{23}$ se interessou por uma série de casos em que "[...] a iniciativa passa pelo diretor e seus atores, não apenas no âmbito da realização do espetáculo, mas, desde o início, quando da elaboração da forma" (Jacquot, 1970, p. 7-17) $)^{24}$. A fim de "dar uma ideia dos procedimentos utilizados para a gênese das obras" (Jacquot, 1970, p. 7-17) (a palavra designa aqui as obras teatrais, as produções cênicas), os pesquisadores se baseiam em observaçóes diretas e, quando isso é possível, em livros de bordo dos criadores $^{25}$. Idealmente, a dimensão textual não devia ser negligenciada, ela devia até mesmo passar novamente para o primeiro plano no qual ela era decisiva. Esse princípio não foi sempre respeitado. Foram necessárias algumas décadas para que se iniciasse um reequilíbrio.

Um outro fenômeno importante é a evolução do arquivamento. Contrariamente ao que se poderia pensar, o fator decisivo não foi o depósito de seus arquivos - no $\mathrm{IMEC}^{26}$ ou na $\mathrm{BnF}^{27}$ - pelos artistas: diretores como Vitez ou Chéreau, responsáveis pelas companhias como Renaud-Barrault, cenógrafos como Jacques Le Marquet. Desde muito tempo tais arquivos estavam disponívei ${ }^{28}$. Os pesquisadores iriam se nutrir disso, sem inscrever para tanto seu trabalho no movimento da 
genética. São os primeiros registros audiovisuais de espetáculos, produzidos nos anos 1970 (o exemplo pioneiro mais famoso é o filme 1789, do Théatre du Soleil, em 1974) que suscitaram ou reforçaram a ideia de um estudo metódico da gênese teatral. Graças ao vídeo ou a câmeras leves, os rascunhos da produção cênica podiam ser fixados por uma mídia que respeitasse a sua dimensão temporal ${ }^{29}$. No entanto, como não se demoraria para se dar conta, o registro audiovisual era uma ilusão, ele modificava o que pretendia fixar objetivamente, ele não era uma garantia de autenticidade, ele náo substituía o jogo da memória. Mas essa ilusão permitira imaginar um projeto, cujos pesquisadores tentam doravante viabilizar os meios.

O fator seguinte diz respeito ao público de teatro (os públicos dos teatros). Desde os anos 1980, segundo o movimento que atinge o conjunto dos campos culturais, os espectadores descobrem um gosto, depois um entusiasmo pelo processo ${ }^{30}:$ o da encenação (a sala de trabalho, o workshop, o training, a improvisação), o da cenografia (maquetes, esboços de cenários e croquis de figurinos). A relação do público com o universo teatral se transforma: os diretores abrem seus ensaios, que se tornam objetos de filmes, de cadernos fotográficos ou de obras ilustradas com documentos de $\operatorname{arquivos}^{31}$; eles criam ou encenam novamente ficçóes genéticas ${ }^{32}$.

Um bom número de performances cênicas contemporâneas não foram fundadas em obras dramáticas, de maneira que o registro teatral perde sua estrutura de organização tradicional. Em uma espécie de reflexo vital favorecido pela tecnologia, os criadores recorrem a um outro tipo de arquivamento. Desses eventos frágeis, eles desejam que tudo seja captado, inclusive os primeiros estratos. Progressivamente, o processo se torna um dos modos de existência de um tipo novo de espetáculo, que pode ser visto em uma sala, acompanhado na Internet, ao vivo e gravado, um espetáculo cujos espaços e tempos são multiplicados. O filme de Jacquie Bablet, Une Génisse en Gésine, dedicado à gênese do espetáculo La Génisse et le Pythagoricien, de Jean-François Peyret, pode ser considerado como uma variação elaborada e estabilizada do itinerário proposto aos internautas no site da companhia $T F 2^{33}$ : fragmentos de registros audiovisuais, dos ensaios disponibilizados na Internet, cobrem todas as fases do trabalho. $\mathrm{O}$ digital, que põe fim a alguns suportes, permite fixar facilmente as tentativas sucessivas de dar forma à encenação durante os ensaios e as versões do texto advindo das improvisaçóes ${ }^{34}$, renovando assim os objetos de estudo dos pesquisadores. 


\section{Entre Genética e Teatro: um novo campo de pesquisa}

A crítica genética está inscrita doravante entre as grandes correntes críticas atuais, entendida, além de suas próprias produçóes científicas, como uma orientação metodológica maior ${ }^{35}$, suas propostas, difundidas por um grande número de trabalhos, de artigos, de publicaçóes ${ }^{36}$, articulam-se de diversas formas com uma grande variedade de pesquisas: o número 26 da revista Genesis, já mencionado, é inteiramente dedicado ao teatro. Ele se abre largamente às diferentes dimensôes da criação (escrita, cenografia, trabalho do ator) e propóe uma síntese teórica atualizada. Em 2004-2006, o seminário geral do ITEM ${ }^{37}$ toma por objeto as gêneses teatrais. Artigos e obras aparecem ${ }^{38}$, cursos são criados, teses e dissertaçóes são produzidas em várias universidades ${ }^{39}$, colóquios são organizados ${ }^{40}$. Pela primeira vez, um verbete Critica genética foi introduzido no Dictionnaire Encyclopédique du Théâtre [Dicionário Enciclopédico do Teatro], em 2008, por ocasião de uma reedição ${ }^{41}$. À antiga separação feita entre gênese do texto e gênese da cena se substitui, desde alguns anos, a uma complementaridade complexa entre uma primeira genética do teatro à francesa, ou europeia, que explora os processos de criação cênica permanecendo fortemente enraizada no estudo dos manuscritos, e uma outra genética, que se funda exclusivamente no estudo dos ensaios. Muito viva na França desde os anos $1980^{42}$, essa segunda corrente encontrou um espaço de desenvolvimento privilegiado no Canadá e no mundo anglófono. Façamos menção aos trabalhos de Gay McAuley (1998) (Universidade de Sidney ${ }^{43}$ ) e de Irène Roy (1993) (Universidade Laval de Quebec ${ }^{44}$ ). Ela se exprime nas conferências anuais da FIRT (Federação Internacional de Pesquisa Teatral), cujo grupo de trabalho se especializou nessa área. Sob a direção de Josette Féral, a revista Theatre Research International publicou em 2008 um número especial, intitulado Genetics of Performance (Féral, 2008) ${ }^{45}$.

\section{Novas Questóes Teóricas}

\section{Intermitências Autorais}

Os primeiros estudos de gênese teatral tinham introduzido a figura do diretor ao lado da figura do escritor-dramaturgo, e esboçado a imagem de uma dupla com tarefas claramente divididas. As análises aprofundadas de documentos que correspondem a diversos momentos precisos da escrita ou do trabalho de palco questionaram 
esse modelo: elas confirmaram primeiro que cada uma das duas figuras podia desaparecer. $\mathrm{O}$ que os historiadores e os etnógrafos sabem desde muito tempo sobre o passado e o estrangeiro vale também para nossa vida teatral: existem espetáculos sem autor e outros sem diretor ${ }^{46}$. Nos casos em que a dupla poderia se manter, os trabalhos dos pesquisadores sobre os arquivos mostram a fragilidade das práticas, o grande número de pessoas e de instituiçóes implicadas, a variedade dos modos de interaçáo, o peso dos fatores humanos imprevistos: isso reduz um pouco o abismo entre os esquemas teóricos e os testemunhos de atores, diretores de cena, diretores de sala, técnicos, encenadores ${ }^{47}$. $\mathrm{O}$ estudo dos primeiros vestígios, por exemplo, correspondente à fase de concepçáo tateante no que ainda é apenas um projeto para o escritor, revela figuras de atores/atrizes que náo farão parte do elenco, mas, que poderão ter contribuído para a obra de maneira decisiva. Esse fenômeno, conhecido em Duras, é menos conhecido em Anouilh. Os arquivos dos lugares que produziram ou receberam a criação cênica afirmam a importância dos dados espaciais e dos parâmetros objetivos das salas e dos palcos. Presenças muitas vezes tratadas como silhuetas de fundo podem ser determinantes: o cenógrafo, o iluminador, o intérprete de um dos papeis, um críticoamigo-acompanhante. Aparecem, assim, binômios ou trinômios artísticos mais ou menos estáveis, cujas decisóes são individualizadas apenas a partir de um distanciamento ulterior e simplificador. Tal cenógrafo assume uma função dramatúrgica; as invençóes de alguns atores inspiram o diretor, como mostram nesta obra os testemunhos, inclusive o de Jaques-Wajman. Esses episódios semicoletivos ou interpessoais, amigáveis, sexualizados, lúdicos, conflitantes contribuem para a elaboração do espetáculo, às vezes, para a escrita, a reescrita ou para a adaptação do texto - se ele existir.

O caráter interartístico da cena contemporânea (que mistura dança, artes plásticas, circo, teatro de objetos) acentua a multiplicação dos polos criativos, mas, a pluralidade da arte teatral é um fenômeno permanente e importante. No momento em que começa realmente o espetáculo, por exemplo, o autor (se ele existir), o diretor (se ele existir), ao qual é preciso às vezes acrescentar o cenógrafo, o criador de luz, o sonoplasta, entre outros, passam a responsabilidade ao conjunto formado pelos atores, eventualmente acompanhados de alguns técnicos: os diretores de cena, os responsáveis pelo maquinário e outras pessoas ativas durante o desenrolar da cena. Antes mesmo que o estado de cena seja atingido, muitas condiçóes interveem na 
gênese. Para que um projeto se firme como tal, é preciso que a um desejo de teatro responda outra voz, ou outras vozes. A censura e a subvenção são formas mais claras da negociação permanente com o social, sem a qual não existe teatro. Tendo em vista o caráter literário de seus objetos iniciais, a genética não inscreveu espontaneamente as questôes de produção (no sentido econômico, comercial, institucional) no núcleo de seus estudos. Sáo os artistas que trataram disso, sem dissociar as implicaçóes materiais e socioculturais daquilo que os críticos descrevem frequentemente como puras decisôes artísticas. A pobreza ou a modéstia das produções não faz desaparecer essa dimensão da gênese. Então, os pesquisadores coletaram e inscreveram nos arquivos genéticos, inclusive os escritos datilografados e os esquemas de implantação, certo número de documentos jurídicos e financeiros. Além do lugar (escolhido, imposto, negociado, de todo modo determinante), esses documentos concernem à cenografia (pedidos, amostras, faturas de materiais), o elenco (listas de atores contratados, contratos, recibos), o número e a duração dos ensaios (plannings), o número e a duração das apresentaçôes, as turnês e as reapresentaçóes eventuais.

Essas novas explorações não tiveram como efeito negar o papel específico do autor nem o do diretor, onde eles existem, mas compreender melhor esse papel: como se manifesta a acuidade artística pela qual um espetáculo encontra sua forma? Como ela se divide entre todos os envolvidos: aqueles que assinam suas intervençóes e cujos nomes estão no programa e que permanecem anônimos? Como se dividem as responsabilidades? A abordagem genética, mais próxima do trabalho, permite relativizar a repartição oficial dos papeis, reduzir alguns clichês.

\section{Cena(s) e Texto(s)}

Em um artigo frequentemente citado, escrito há mais de vinte e cinco anos, Bernard Dort ${ }^{48}$ indicava que era preciso parar de pensar as relaçóes do texto e da cena "como relaçóes entre duas entidades, impenetráveis entre si" (Dort, 1995, p. 243-275). Em breve, acrescentava Dort, evocando depois de Patrice Pavis uma "revolução copernicana", o longo debate que reunia e opunha esses termos "náo estará mais longe de ficar sem objeto" (Dort, 1995, p. 243-275). Dort mostra primeiro a existência de laços genéricos entre um e outro, por um lado com "a cena na escrita" (1995, p. 243-275) (reconhecida pelos 
piores logocêntricos, Aristóteles e Hegel), e por outro lado com "o texto de um teatro sem texto" (1995, p. 243-275) (do qual Craig e Artaud seriam os mais brilhantes representantes). Ele lembra que, em matéria de espetáculo dramático, não é necessário falar do texto, pois existem dois deles, o texto didascálico e o texto falado ${ }^{49}$. Ele evoca então a "revolução einsteiniana" que atinge a cena contemporânea: "o teatro [...] não tem mais centro. Ou melhor, ele tem vários, diferentes, segundo seus modos de exercício" (Dort, 1995, p. 243-275) ${ }^{50}$. Dort toma dois exemplos: Catherine (1976), "teatro-narrativa" adaptado do romance de Aragon Les Cloches de Bâle por Antoine Vitez - um diretor que costumava dizer que não podia montar um espetáculo sem escrevê-lo-, e Berceuse, de Samuel Beckett - um autor cuja escrita, diz Dort, "faz entrar [a cena] no texto" (Dort, 1995, p. 243-275). Assim, é ilustrada a ideia de uma redistribuição completa das funções de todos os componentes cênicos. $\mathrm{O}$ texto náo tem mais dois modos de existência (o diálogo/as rubricas), mas uma pluralidade de entradas e de usos. A confrontação mudou de natureza: ela concerne "[...] o lugar do escrito e do permanente em um acontecimento concreto e efêmero" (Dort, 1995, p. 243-275).

Quase vinte anos mais tarde, a situação é paradoxal: a noção de teatro pós-dramático, os ataques contra Aristóteles, tido como responsável pela maneira como o texto teria deixado pobre a cena ocidental (Lehmann, 2002; Dupont, 2007) ${ }^{51}$, atestam a excelente resistência das velhas categorias. Podem-se ler respostas a essas propostas - que querem, sobretudo, marcar os espíritos (o conteúdo dos trabalhos é bem mais nuançado) -, mas, salvo exceções ${ }^{52}$, essas defesas do texto são formuladas do interior de disciplinas que separam a priori as questôes textuais das questóes cênicas. Uma das consequências observáveis da atenção voltada ao teatro pela crítica genética é ter provocado a reaproximação desses universos, fazendo dialogar discursos que se constituíram de modo quase autônomo.

Antes de abordar esse papel mediador, os geneticistas tiveram de rever seus modelos e seus métodos: seus primeiros estudos supunham a linearidade cronológica do processo, do texto redigido ao texto impresso e do texto impresso ao texto encenado. Linearidade questionada desde as primeiras observaçóes de arquivos do século XX: em inúmeros casos, com efeito, o texto dramático é modificado, até mesmo composto parcialmente ou totalmente durante os ensaios. Os historiadores confirmaram a necessidade dessa revisão, uma vez que durante séculos o texto foi impresso somente quando ele 
era feito, depois da apresentação. O modelo genético inicial é então repensado no sentido de uma complexidade muito maior. O "velho esquema texto/cena" cede lugar a um "modelo dinâmico" em que os dois elementos "permanecem, em todos os momentos da criação, interdependentes entre si" (Grésillon; Thomassseau, 2006) ${ }^{53}$. O que corresponderia, para retomar a imagem de Dort, a uma mudança "copernicana". Entretanto, o polo textual náo deixa de ser implicitamente dominante. Se o trabalho de palco é levado em conta, "a obra teatral" continua a ser definida como o conjunto de encenaçóes sucessivas de uma mesma obra dramática.

Ora, essa definição não é unânime. Para os especialistas em teatro, a partir do momento em que a encenaçáo se torna uma arte específica, a realizaçáo do espetáculo adquire uma verdadeira autonomia estética com relação à produção do repertório dramático e o termo obra teatral designa o conjunto do trabalho original de um criador cênico (Giorgio Strehler, Peter Brook, Robert Wilson, etc.) ${ }^{54}$. Ao estudo genético do conjunto das encenaçóes elaboradas a partir de um mesmo texto, deveria logo poder-se acrescentar o estudo do conjunto dos espetáculos de um mesmo diretor. Nesse segundo caso, é no início da produção cênica que o texto muda de função: a escolha de uma peça se inscreve em um procedimento preexistente que é o do diretor; a peça vem responder à busca de um elemento cristalizador, vem ajustar-se a uma matriz anterior de formas, de ideias e de imagens. Cada vez mais frequente, na atualidade, o diretor fabrica ou faz fabricar um texto correspondente a seu projeto, às vezes a partir de uma base existente (os escritos de Foucault, no espetáculo evocado nesta obra por Jean Jourdheuil).

Os depoimentos e estudos reunidos nesta obra provarão, talvez, ao leitor a necessidade de um novo modelo teórico, mais einsteiniano ainda que o de Dort. Esse modelo deveria poder acolher a enorme diversidade dos casos de figura repertoriadas na história, da Idade Média ${ }^{55}$ à modernidade, do texto não encenável, ou nunca encenado, à performance desprovida de todo elemento textual. Deve-se ainda integrar a ideia segundo a qual não se pode estabelecer distinção clara entre o textual e o cênico, distinçáo mantida in extremis por Bernard Dort, que identificava o primeiro com a performance e o segundo com o efêmero. Ao exigir a coleta igualitária de todos os documentos de trabalho escritos (manuscritos do autor, cadernos do diretor, notas de atores, registros técnicos, etc.), as regras da constituição do 
dossiê genético convidam a rever as categorias do textual e do cênico. De que lado colocar os livros de diretor de Stanislavski, que afirma sua nova função redigindo-os cuidadosamente ${ }^{56}$ Como classificar o rascunho magnífico, um exemplar do romance L'Amante Anglaise (A Amante Inglesa) de Marguerite Duras, que o ator Michael Lonsdale utiliza como registro de ensaio?57 Que fazer dos Arbeitsbücher, compostos no início do projeto Foucault por Mark Lammert, cenógrafo e colaborador de Jean Jourdheuil, que os evoca aqui mesmo? Quanto à estabilidade do texto dramático, a abordagem genética, sabe-se, tem eficazmente questionado. Assim, esta obra concebe um modelo flexível, de nível triplo, levando em conta respectivamente o caráter estrutural, movente e multiforme do escrito.

\section{Inacabamentos}

Inversamente à perspectiva clássica, a abordagem genética sublinha "a fragilidade do modelo de obra 'acabada" (Hay, 1986, p. 7) ${ }^{58}$, qualquer que seja o domínio artístico envolvido. Essa proposta, que constituiu um dos dados teóricos maiores da disciplina, foi verificada e precisada ao longo dos anos, tendo sido aplicada pelos pesquisadores a objetos diversos ${ }^{59}$. Podemos constatar doravante o efeito do objeto sobre o método: obedecendo à estética do non finito, o texto de $L a$ Mise en Euvre, por exemplo, continuação de Eléments de Critique Génétique, já mencionados, se prolonga em Coda intitulada Perpetuum mobile, que conduz o leitor à imagem em rotação de um pião textual (Grésillon, 2008) ${ }^{60}$. Sinal de que a noção de inacabamento não perdeu nada de sua importância, um longo artigo deve lhe ser consagrado no Dictionnaire de Critique Génétique em preparação no ITEM.

Se a hipótese do inacabamento provocou uma reviravolta no plano teórico literário, é porque o texto de um poema, ou o de um romance, podia parecer fechado. Nunca aconteceu o mesmo para o caso da representação teatral, menos ainda para o caso do texto dramático, que a encenação moderna teve paradoxalmente tendência a constituir como um objeto estável, mas que, redigido para a encenaçáo, apresentou-se sempre como um conjunto aberto, que se podia modificar, ampliar ou reduzir, sendo que Pirandello representa nessa área um caso extremo (Budor, 2010) ${ }^{61}$. O termo inacabamento serve correntemente para designar uma das grandes características da arte teatral, a mesma que às vezes hesita em classificá-la entre as 
artes: pode-se qualificar como obra o que existiria apenas por meio de uma sequência de eventos únicos, de performances efêmeras e concebidas para um espectador ${ }^{62}$ ?

A abordagem genética, que permite comparar os diversos modos como as artes se acabam, ajuda a precisar a originalidade do teatro nessa área. A princípio, ele associa várias formas de inacabamento: o não produzido (o texto de teatro, como se sabe, é duplamente furado: as rubricas demandam serem traduzidas cenicamente, o diálogo deve ser proferido e a própria cena é o lugar do como se. Nada, nunca, realiza-se aí); o não fixado (nenhuma apresentação é idêntica à outra); o incompleto (o espectador tem sua parte no desenvolvimento da apresentação); o nunca terminado (ver a frase de Vilar citada no início deste artigo).

Essa tipologia é acurada graças aos estudos particulares. Distingue-se, por exemplo, no teatro ocidental moderno, várias etapas codificadas de fixação (ou de não fixação) de produção: a etapa que precede o encontro do espetáculo com o público, ela mesma modulada pela couturière ${ }^{63}$, a generale e la première; uma segunda etapa, que segue imediatamente esse encontro: as reaçóes do público que, então, guiam os praticantes na correção do trabalho; enfim, todas as fases que correspondem às reapresentaçóes. Da mesma forma, existe uma grande variedade de respostas à incompletude da encenação: cada noite, o espetáculo renasce, pois os atores são bem vivos e os espectadores sempre diferentes. As apresentaçóes sucessivas não devem, portanto, ser consideradas como ocorrências de um objeto estético acabado, mas como tantas gêneses multiplicadas no tempo. Aqui intervém o que Mathias Langhoff chama de "a segunda aparição" do teatro, segundo ele, sua "verdadeira aparição", aquela que resulta da "ruminação" do espetáculo pelos espectadores, "[...] o teatro rememorado, filtrado e lavado na vida de todos os dias" (Langhoff, 2006, s. p. $)^{64}$. Assim, o teatro, que partilha alguns dos seus traços com duas outras artes recentemente observadas pelos geneticistas (a relação física com o espaço que instala a arquitetura, a multiplicidade dos sistemas de sinais e participantes que o cinema conhece), manifesta aí uma verdadeira originalidade genética.

O inacabamento do teatro é tal que ele torna seu arquivamento ao mesmo tempo muito mais necessário que nas outras artes, mas, também, bem mais problemático. Como náo querer acumular os traços do que vai se desfazer? Mas, como parar uma dinâmica infinita sem trair a própria natureza do teatro? Em agosto de 2008, o con- 
gresso da SIBMAS ${ }^{65}$ concentrou-se precisamente nessa dificuldade. Seu título era Captar a essência do espetáculo: um grande desafio para $o$ patrimônio imaterial ${ }^{66}$. Na chamada à comunicação, o primeiro problema proposto pelos organizadores foi a materialidade e o caráter limitado dos vestígios obtidos:

Dar visibilidade a essa atividade com o auxílio de apenas objetos estáticos desemboca em um depoimento parcial, não plenamente satisfatório. Para reconstituir a experiência de uma encenação que aconteceu, é de capital importância servir-se de registros audiovisuais do espetáculo, de testemunhos orais e outras técnicas ${ }^{67}$.

Os novos meios evocados também apresentam outros problemas espinhosos: é possível captar o próprio evento teatral ${ }^{68}$ ? O registro audiovisual é sempre suspeito de destruir a lembrança, ele tende a substituir-se à impressão da sensação do espectador, a torná-la vaga, a apagá-la. A fim de restituir fielmente o espetáculo tal como ele existiu concretamente, isto é, tal como o público pôde vivê-lo, os diretores multiplicaram as tentativas. Depois de Antoine Vitez, ou, muito diferentemente, Tadeusz Kantor ou Ariane Mnouchkine, Patrice Chéreau, Matthias Langhoff, Romeo Castellucci e outros, filmam eles mesmos ou escolhem produtores com quem eles podem pensar a recriação audiovisual. Os êxitos, mais numerosos que se podia pensar, permanecem completamente imprevisíveis. Régy, que proíbe toda filmagem, encontrou alguma coisa de sua Mort de Tintagiles (1997) em alguns minutos de imagens sonoras em preto e branco, excepcionalmente registrados em condiçóes improváveis. A fotografia, aparentemente menos discutível, pode também se tornar uma armadilha. Quanto aos arquivos puramente sonoros, depois de terem sido completamente ignorados, eles suscitam uma abordagem teórica específica, que está ainda no início ${ }^{69}$. Parece paradoxalmente ser mais simples restituir a variabilidade da escrita, quase palpável nos rascunhos, que a mobilidade da cena.

A continuação do texto da SIBMAS se refere à abordagem genética como a uma solução possível. Integrar o movimento da preparação da obra cênica no processo de arquivamento aparece aos curadores das bibliotecas e museus de teatro como um meio de desfazer o mecanismo de petrificação. "Mas, é possível, eles se interrogam, intrometer-se no atelier do artista ou no processo de ensaio?” Esse assunto suscitou tomadas de posição muito diversas. Jacques Lassalle, em sua contribuiçáo, expõe como e por que seu 
próprio ponto de vista evoluiu ${ }^{70}$. Finalmente, o problema parece envolver menos a aceitação dos pesquisadores nas salas de ensaio do que a maneira como eles vão proceder para respeitar o movimento do processo melhor do que o movimento da apresentação: a gravação dos ensaios suscitou recentemente algumas pesquisas audaciosas ${ }^{71}$; quanto às práticas de observação de tipo etnográfico, mais antigas, elas são objeto de uma reflexão por parte de alguns diretores. Os dispositivos imaginados por eles solicitam obrigatoriamente a memorizaçáo pessoal do observador ${ }^{72}$. Assim, nesse tratamento do inacabamento constitutivo do teatro, experimenta-se a conciliaçáo entre desejo de arquivo e respeito pelo vivido.

É à medida desses novos traçados que importa apreciar os efeitos do diálogo entre geneticistas e pessoas de teatro, que está na origem da concepção desta obra. De um modo ou de outro, a troca se revelou estimulante. Os geneticistas desejaram ir em direção ao teatro. As pessoas de teatro (sejam criadores, praticantes da cena ou pesquisadores que acompanham o espetáculo) colocaram diante dos geneticistas uma matéria heterogênea, indócil à análise genética e que exige, entretanto, ser tratada com instrumentos de pesquisa adaptados. Essa dificuldade não se mostrou insuperável, uma vez que a abordagem genética já provara sua flexibilidade (flexibilidade que náo exclui o rigor) para apreender outros objetos para além do manuscrito literário. No entanto, a concretude temporal e espacial da apresentaçáo, a materialidade dos objetos cênicos e do corpo do ator, assim como a força das sensações experimentadas pelo espectador, questionaram de maneira inédita a questáo da presença do pesquisador junto a seu objeto de estudo. Longe de se limitar à constataçáo da diversidade das pessoas que testemunham o processo, longe de lembrar simplesmente que uma parte essencial da criação escapa sempre a toda percepçáo e a análise, a reflexão estendeu-se a um questionamento teórico sobre o status e o poder do arquivo diante do efêmero constitutivo do teatro. Os geneticistas incitaram as pessoas de teatro, certamente habituados a coletar os vestígios dessa arte fugaz, a não negligenciar nenhum deles, mesmo que fosse o mais ínfimo, e a definir assim a composiçấo do dossiê genético de teatro: tratava-se de pôr esse olhar impiedoso náo sobre a obra teatral, mas sobre um processo sem fim, e de pôr em dia a estruturação disso na sua tensão em direção ao inacabamento. 


\section{Notas}

${ }^{1}$ Este artigo é a adaptação e tradução da clássica introdução sobre Genética Teatral publicada em Grésillon; Mervant-Roux; Budor (2010). O texto, assinado pelas três professoras, constitui a introduçáo teórica da obra. Apresenta-se aqui uma versáo ligeiramente resumida com alguns parágrafos suprimidos.

${ }^{2}$ No original: [U]ne confusion des sons, des choses et des êtres. Une sorte d'interminable brouillon où l'ouvre se recherche, en empruntant à toutes les libertés du jour et de la nuit. "Trente-trois propos sur Avignon", em Le Théâtre, service public, apresentação e notas de Armand Delcampe, Paris, NRF, Gallimard, "Pratique du Théâtre", 1975, p. 455.

${ }^{3}$ N. R.: preferimos manter a palavra "obra" que no original se refere ao livro o qual esta introdução apresenta.

${ }^{4}$ Este binômio se fixa e se cristaliza nos anos 1970, momento em que o estudo do trabalho teatral se define contra o estudo do texto, flexibiliza-se nos anos 1980, torna-se objeto de críticas convergentes nos anos 1990.

${ }^{5}$ Conforme a proposta antropológica de Élie Konigson (2001).

${ }^{6} \mathrm{O}$ esquecimento dos arquivos sonoros pela pesquisa (o microfone e a vitrola foram inventados no mesmo período) é atualmente um estudo específico (Grésillon; MervantRoux; Budor, 2010a).

7 No original: Son objet: les manuscrits littéraires, en tant qu'ils portent la trace d'une dynamique, celle du texte en devenir. Sa méthode: la mise à nu du corps et du cours de l'écriture, assortie de la construction d'une série d'hypothèses sur les opérations scripturales. Sa visée: la littérature comme un faire, comme activité, comme mouvement (Grésillon, 1994, p. 7).Ver também Biasi (2000).

${ }^{8}$ No original: “écrire, ajouter, supprimer, remplacer, permuter" (Grésillon, 1994, p. 7).

${ }^{9}$ Ver respectivamente os números 14, 20, 24, 28 da revista Genesis. Manuscrits, Recherche, Invention, Paris: Jean-Michel Place.

${ }^{10}$ Ver Hay, 1994, p. 11-23.

${ }^{11}$ Gérard Genette, “Ce que nous disent les manuscrits”, Le Monde, 17 nov. 1989.

12 Ela nasceu na França, nos anos 1960.

${ }^{13}$ Akakia-Viala, Édition critique d'une mise en scène romantique. Indications générales pour la mise en scène de Henri III et sa cour, drame historique en cinq actes, en prose, de M. A. Dumas por Albertin, Paris: Livraria E. Droz, 1938.

${ }^{14}$ A obra de Paul Dimoff, "La Genèse de Lorenzaccio", Paris: E. Droz, "Société des textes français modernes”, data de 1936.

${ }^{15}$ Ver Proust, 2006, p. 165-168.

${ }^{16}$ Dort, 1972, p. 109-255.

${ }^{17}$ Ver Thomasseau, 1984, p. 99-121; Autant-Mathieu (Org.), 1995; Gallèpe, 1998.

${ }^{18}$ Mervant-Roux, 2000, p. 363-388. 
${ }_{19}$ Por "análise de espetáculo", Josette Féral entende um tipo de abordagem meticulosa, principalmente semiológica, da realização cênica. Segundo Patrice Pavis, esse tipo de análise consiste em descrever "o texto espetacular", em "compartimentá-lo segundo todos os tipos de critérios: narrativos, dramatúrgicos, gestuais e prosódicos”. Ver Pavis, 1996, p. 320.

${ }^{20}$ Féral, 1998, p. 54-59.

${ }^{21}$ Ver Grésillon, 1996, p. 71-93.

${ }^{22}$ No original: de ramener l'étude du théatre à celle d'un genre littéraire.

${ }^{23}$ N. T.: Centre National de Recherche Scientifique (Centro Nacional de Pesquisa Científica).

${ }^{24}$ No original: l'initiative passe au metteur en scène et à ses comédiens, non plus seulement au stade de la réalisation du spectacle, mais dès le début, lors de l'élaboration de la forme.

${ }^{25}$ Jacquot, 1970, p. 7-17.

${ }^{26}$ N. T.: Institut Mémoires de l'Édition Contemporaine (Instituto de Memórias da Edição Contemporânea).

${ }^{27}$ N. T.: Bibliothèque Nationale de France (Biblioteca Nacional da França).

${ }^{28}$ As autoras remetem à contribuição de Noëlle Guibert na obra: "Objets de la genèse théâtrale", p. 89-106.

29 Ver Odette Aslan, La Direction d'acteurs: Giorgio Strehler répète La Trilogie de la villégiature de Goldoni avec les Comédiens français, CNRS, SERDAVV, 1979, 54 min. Michèle Porte, Savannah Bay c'est toi, autor e diretor: Marguerite Duras, com Madeleine Renaud, Bulle Ogier [et al.], [Bry-sur-Marne], INA, cop. 1983, 69 min.

${ }^{30}$ Danièle Sallenave fala sobre isso no capitulo intitulado "De l'esquisse", de sua obra Les Épreuves de l'art, Arles, Actes Sud, "Le temps du théâtre", 1988, p. 29-38.

31 Três exemplos: o filme de Stéphane Metge sobre a preparação do espetáculo Dans la solitude des champs de coton por Chéreau (Une autre solitude, 1996); a reportagem fotográfica de Jacquie Bablet sobre os ensaios de Trois sours de Tchekhov por Langhoff (Théâtre/public, n. 122, Odette Aslan (org.), mar./abr. 1995); a obra de Le Médecin malgré lui. Le Médecin volant com ilustraçóes de Dario Fo, retiradas de seus cadernos de encenação [ComédieFrançaise, 9 juin 1990], Paris, Imprimerie nationale, "Le spectateur français", 1991.

${ }^{32}$ Ver a lista das obras cinematográficas e teatrais reunidas com essa denominaçáo em Genesis, n. 26, 2006, p. 186. Dentre as mais conhecidas: Après la répétition (Ingmar Bergman, 1985), Elvire-Jouvet 40 (Brigitte Jaques, 1986).

${ }^{33}$ N. R.: Grupo teatral francês dirigido por Jean-François Peyret.

34 "Ça bouge beaucoup. Sans ordinateur, nous n'y arriverions pas. Il faudrait une batterie de secrétaires la nuit qui retaperaient tout. C'est un théâtre contemporain de l'ordinateur" (Isso muda muito. Sem computador, não teríamos conseguido. Seria necessário um grupo de secretários durante a noite para digitar tudo. É um teatro contemporâneo de computador) (Peyret, 2006, p. 130).

${ }^{35}$ Daniel Bergez, discurso sobre o trabalho destinado aos estudantes de Letras, Introduction aux méthodes critiques pour l'analyse littéraire, Paris, Dunod, 1999 [1990], p. 2. Outras quatro correntes são apresentadas: psicanalítica, temática, sociológica, linguística. 
${ }^{36}$ Ver, sobretudo, o site do ITEM (Institut des textes et manuscrits, Instituto de textos e manuscritos). Disponível em: <http://www.item.ens.fr/>.

${ }^{37}$ N. R.: Institut des Textes et Manuscrits Moderne (Instituto de Textos e Manuscritos Modernos) do CNRS et ENS (École Normale Supérieure)

${ }^{38}$ Inclusive sobre formas cênicas anteriores à encenação. Por exemplo: Lochert, 2009. Ver também as publicaçôes do ARIAS-CNRS; os documentos temáticos de Théâtre/Public (entre outros, Guinebault-Szlamowicz (org.), Cenografia, trabalho e obra, n. 177, 2005); os de OutreScène, revista do Teatro Nacional de Estrasburgo; os "Carnets de création" de Théâtre s en Bretagne, puis de ThéâtreS (ver a lista das revistas citadas na bibliografia de Genesis n. 26 já mencionada).

39 Por exemplo: De Lorenzis; Lassalle, 1999; Bernard, 2000; Landis, 2001.

${ }^{40}$ Por exemplo, o colóquio internacional "Parcours de Génétique Théâtrale: de l'atelier d'écriture à la scène", Universidade de Lisboa, 9-11 de dezembro de 2009.

${ }^{41}$ Os redatores deste são Jean-Yves Vialletton e Jean-Marie Thomasseau. Ver Corvin (org.), 2008 [1991], p. 384-386.

42 Ver Banu (org.), 2005.

${ }^{43}$ McAuley, 1998, p. 75-85.

${ }^{44}$ Roy, 1993.

${ }^{45}$ Theatre Research International, vol. XXXIII, n. 3, Féral (org.), Cambridge, UK, setembro 2008.

${ }^{46}$ As autoras remetem às contribuições de N. Guibert (já citado) e J.-M. Thomasseau. "Pour une génétique du théâtre non contemporain", p. 233-248.

47 "Déconstruction", o texto escrito por Claude Régy para o volume 23 das VCT consagrado a seu teatro (Editions du CNRS, 2008), é uma brilhante descrição de uma indescritível gênese.

${ }^{48}$ Dort, "Le texte et la scène. Pour une nouvelle alliance" (O texto e a cena. Por uma nova aliança), em Encyclopadia Universalis, Supplément II, "Les enjeux" (Os desafios), 1984, reeditado em Le Spectateur en dialogue (O espectador em diálogo), Paris, P.O.L, 1995, p. 243-275.

${ }^{4}$ Sobre esse assunto, ver Jean-Marie Thomasseau, (1980) 2003, nova edição, p. 91-98.

${ }^{50}$ No original: le théâtre [...] n'a plus de centre. Ou plutôt, il en a plusieurs, différents, selon ses modes d'exercice.

${ }^{51}$ Lehmann, 2002; Dupont, 2007.

${ }^{52}$ Façamos menção a Jean Jourdheuil (2009, p. 59), "Chacun pour soi dans les eaux tièdes du management européen" (Cada um por si nas águas mornas do management europeu).

${ }^{53}$ Grésillon; Thomasseau, 2006, p. 19-34.

${ }^{54}$ A partir de 1983, a coleção Les Voies de la Création Théâtrale, já mencionada, organiza seus volumes por diretor. 
55 Ver por exemplo "La place du Weinmarkt à Lucerne; remarques sur l'organisation d'un espace dramatisé" (O lugar do Weinmarkt em Lucena; observações sobre a organização de um espaço dramático), em Élie Konigson (org.), 1980, p. 43-90.

${ }^{56}$ Como mostra, nesta obra, Autant-Mathieu: "Tchekhov/ Stanislavski ou la naissance de la mise en scène", p. 179-194.

57 Ver neste mesmo número a tradução de: Grésillon; Mervant-Roux: "Marguerite Duras/ Claude Régy: L’Amante Anglaise. Genèse d'une écriture, gésine d'un théâtre” p. 211-232.

${ }^{58}$ Hay, 1986, p. 7.

${ }_{59}$ Por exemplo, Lebrave, 2001, p. 19-27. Budor, 2000, p. 183-193.

${ }^{60}$ Grésillon, 2008, p. 295-304.

${ }^{61}$ Como mostra D. Budor, na obra: "Le chantier Pirandello", p. 107-122.

${ }^{62}$ Entre outros, o argumento de Michel Fried em seu célebre texto antiteatral: "Art et objectité”, [1967] 2007, p. 113-140.

${ }^{63}$ N.R.: Existem em francês três dias importantes para a estreia do espetáculos: la couturière, ensaio técnico geral; la generale, ensaio geral, normalmente com convidados e imprensa; e, la première, a estreia propriamente dita.

${ }^{64}$ Le théatre est selon moi comme la nourriture pour les boufs: ce n'est qu'après avoir été longuement ruminé qu'il devient une véritable alimentation. Para mim, o teatro é como a comida para os bois: é apenas depois de uma longa ruminação que ele se torna um verdadeiro alimento. (Matthias Langhoff, participação do seminário geral do ITEM, "Genèses théâtrales", ENS, 6 de março de 2006).

${ }^{65}$ No original: Société internationale des bibliothèques et des musées des arts du spectacle (Sociedade internacional das bibliotecas e dos museus das artes do espetáculo).

${ }^{66}$ No original: Capter l'essence du spectacle: un enjeu de taille pour le patrimoine immatériel.

${ }^{67}$ No original: Donner à voir cette activité à l'aide de seuls objets statiques débouche sur un témoignage partiel, pas pleinement satisfaisant. Pour reconstituer l'expérience d'une représentation qui a eu lieu, il est capital de se servir de captations du spectacle, de témoignages oraux et d'autres techniques.

${ }^{68}$ Ver, sobretudo, Picon-Vallin, 1997.

${ }^{69}$ Sobre o uso genético dos arquivos sonoros, ver Van Drie, "Quand la radio fait du théâtre. Le Douzième Coup de minuit (1933)" (2008, p. 50-58).

${ }^{70}$ Sobre a "estratégia" becketiana, ver Van Hulle, "L'Obscène et la (dé)composition textuelle dans l'œuvre théâtrale de Samuel Beckett”, p. 143-155.

${ }^{71}$ Como a captação integral (220 horas) por Pascal Bouchez dos ensaios de Daniel Mesguisch para Bérénice.

${ }^{72}$ Um exemplo: Rostain, 1985, p. 191-218. 


\section{Referências}

ALLEVY, Marie-Antoinette (pseud. Akakia-Viala). Édition critique d'une mise en scène romantique, indications générales pour la mise en scène de 'Henri III et sa cour' (drame historique en cinq actes, en prose, de M. A. Dumas). Paris: E. Droz, 1938.

ASLAN, Odette. La Direction d'Acteurs: Giorgio Strehler répète La Trilogie de la villégiature de Goldoni avec les Comédiens français. Paris: CNRS, SERDAVV, 1979. 54 min.

AUTANT-MATHIEU, Marie-Christine (Org.). Écrire pour le Théâtre. Les enjeux de l'écriture dramatique. Paris: Editions du CNRS, 1995.

AUTANT-MATHIEU, Marie-Christine. Tchekhov/Stanislavski ou la Naissance de la Mise en Scène. In: GRÉSILLON, Almuth; MERVANT-ROUX, Marie-Madeleine; BUDOR, Dominique (Org.). Genèses Théâtrales. Paris: CNRS Éditions, 2010. P. 179-194.

BANU, Georges (Org.). Les Répétitions. De Stanislavski à aujourd'hui. Arles: Actes Sud/ Alternatives théâtrales/Académie expérimentale du théâtre, 2005.

BERGEZ, Daniel. Introduction aux Méthodes Critiques pour l'Analyse Littéraire. Paris: Dunod, 1999 [1990].

BERNARD, Judith. Rhétorique du Discours de Mise en Scéne: mythes et pratiques de la parole dans les répétitions de théâtre. Lyon: Lyon 2: 2000.

BIASI, Pierre-Marc de. La Génétique des Textes. Paris: Nathan Université, 2000.

BUDOR, Dominique. Le Chantier Pirandello. In: GRÉSILLON, Almuth; MERVANTROUX, Marie-Madeleine; BUDOR, Dominique (Org.). Genèses Théâtrales. Paris: CNRS Éditions, 2010.

BUDOR, Dominique. Les Récits de Naissance de Pirandello. In: LEJEUNE, Philippe; VIOLLET, Catherine (Org.). Genèses du Je. Manuscrits et Autobiographie. Paris: CNRS éditions, 2000. P. 183-193.

CONTAT; Michel; FERRER, Daniel Ferrer (Org.). Pourquoi la Critique Génétique? Méthodes, théories. Paris: CNRS Éditions, 1998.

CORVIN, Michel (Org.). Dictionnaire Encyclopédique du Théâtre à Travers le Monde. Paris: Bordas / SEJER, 2008.

DE LORENZIS, Angela; LASSALLE, Jacques. Les Répétitions. Paris: Université Paris 3, 1999.

DIMOFF, Paul. La Genèse de Lorenzaccio. Paris: E. Droz, 1936. (Société des Textes Français Modernes).

DORT, Bernard. Le Texte et la Scène. Pour une nouvelle alliance. In: Encyclopædia Universalis, Supplément II, Les enjeux, 1984. (Reeditado em Le Spectateur en Dialogue. Paris: P.O.L, 1995. P. 243-275).

DORT, Bernard. Lecture de Galilée. Étude de trois états d'un texte dramatique de Brecht. In: BABLET, Denis; JACQUOT, Jean (Org.). Paris: Éditions du CNRS, 1972. P. 109-255. (Coleção Les Voies de la Création Théâtrale, vol. III). 
DUPONT, Florence. Aristote ou le Vampire du Théâtre Occidental. Paris: FlammarionAubier, 2007.

FÉRAL, Josette (Org.). Theatre Research International, Cambridge, UK, v. XXXIII, n. 3, set. 2008.

FÉRAL, Josette. Pour une Étude Génétique de la Mise en Scène. Théâtre/Public, Gennevilliers, n. 144, p. 54-59, nov./dez. 1998.

FRIED, Michel. Art et Objectité. In: FRIED, Michel. Contre la Théâtralité. Du Minimalisme à la Photographie Contemporaine. Paris: Gallimard, NRF, 2007. P. 113-140.

GALLÈPE, Thierry. Didascalies: les mots de la mise en scène. Paris: L'Harmattan, 1998.

GENETTE, Gérard. Ce que nous Disent les Manuscrits. Le Monde, Paris, 17 nov. 1989.

GRÉSILLON, Almuth. De l'Écriture du Texte de Théâtre à la Mise en Scène. Cahiers de Praxématique, Praxiling, Montpellier III, Université Paul Valéry, n. 26, p. 71-93, 1996. (Les Mots et la Scène).

GRÉSILLON, Almuth. Éléments de Critique Génétique. Lire les manuscrits modernes. Paris: PUF, 1994.

GRÉSILLON, Almuth. La Mise en Euvre. Itinéraires Génétiques. Paris: CNRS éditions, 2008.

GRÉSILLON, Almuth; MERVANT-ROUX, Marie-Madeleine. Marguerite Duras/Claude Régy: L'Amante Anglaise. Genèse d'une écriture, gésine d'un théâtre. In: GRÉSILLON, Almuth; MERVANT-ROUX, Marie-Madeleine; BUDOR, Dominique (Org.). Genèses Théâtrales. Paris: CNRS Éditions, 2010. P. 211-232.

GRÉSILLON, Almuth; MERVANT-ROUX, Marie-Madeleine; BUDOR, Dominique. Les archives sonores de L'Amante anglaise [TNP, 1969, mise en scène de la création]. In: GRÉSILLON, Almuth; MERVANT-ROUX, Marie-Madeleine; BUDOR, Dominique (Org.). Genèses Théâtrales. Paris: CNRS Éditions, 2010a.

GRÉSILLON, Almuth; MERVANT-ROUX, Marie-Madeleine; BUDOR, Dominique. Pour une Génétique Théâtrale: prémisses et enjeux. In: GRÉSILLON, Almuth; MERVANT-ROUX, Marie-Madeleine; BUDOR, Dominique (Org.). Genèses Théâtrales. Paris: CNRS Éditions, 2010b. P. 5-23.

GRÉSILLON, Almuth; THOMASSEAU, Jean-Marie. Scènes de Genèses Théâtrales. Genesis, Paris, Jean-Michel Place, n. 26, p. 19-34, 2006.

GUINEBAULT-SZLAMOWICZ, Chantal (Org.). Scénographie: l'ouvrage et l'oeuvre. Théâtre/Public, Gennevilliers, n. 177, 2005.

HAY, Louis. Critiques de la Critique Génétique. Genesis, Paris, n. 6, p. 11-23, 1994.

HAY, Louis. Écrire ou Communiquer? Quelques remarques pour commencer. In: HAY, Louis (Org.). Le Manuscrit Inachevé. Écriture, création, communication. Paris: CNRS éditions, 1986. P. 7. 
JACQUOT, Jean. Présentation. Paris: CNRS, 1970. P. 7-17. (Coleção Les Voies de la Création Théâtrale, v. I).

JOURDHEUIL, Jean. Chacun pour soi dans les Eaux Tièdes du Management Européen. Frictions. Théâtres, Écritures, Paris, n. 15, p. 59, 2009.

KONIGSON, Élie (Org.). Théâtre, Histoire, Modèles. Recherches sur les Textes Dramatiques et les Spectacles du Xve au XVIII ${ }^{e}$ Siècle. Paris: Ediçóes do CNRS, 1980. P. 43-90. (Coleção Arts du Spectacle/Les Voies de la Création Théâtrale, v. VIII).

KONIGSON, Elie. Genèse de l'Image sur Scène. In: PICON-VALLIN, Béatrice (Org.). La Scène et les Images. Paris: CNRS Editions, 2001. P. 32-34. (Coleção Arts du Spectacle/ Les Voies de la Création Théâtrale, v. 21).

LANDIS, Johannes. Performance, Fiction Thématique: le processus créatif vitézien, une tentative de modélisation. Paris: Paris X - Nanterre, 2001.

LEBRAVE, Jean-Louis. L'Écriture Inachevée. In: BUDOR, Dominique; FERRARIS, Denis (Org.). Objets Inachevés de l'Écriture. Paris: Presses de la Sorbonne Nouvelle, 2001. P. 19-27.

LEHMAnn, Hans-Thies. Le Théâtre Postdramatique. Traduzido do alemão por Philippe-Henri Ledru. Paris: L'Arche, 2002.

LOCHERT, Véronique. L'Écriture du Spectacle. Les didascalies dans le théâtre européen aux XVIe et XVIIe siècles. Genève: Droz, 2009.

McAULEY, Gay. Towards an Ethnography of Rehearsal. New Theatre Quarterly, Cambridge University Press, n. 53, p. 75-85, 1998.

MERVANT-ROUX, Marie-Madeleine. La Création du Square: un bouleversement invisible. In: BURGELIN, Claude; GAULMYN, Pierre de (Org.). Lire Duras. Lyon: Presses universitaires de Lyon, 2000. P. 363-388.

PAVIS, Patrice. Sémiologie Théâtrale. In: Dictionnaire du Théâtre. Paris: Dunod, 1996. P. 320 .

PICON-VALLIN, Béatrice (Org.). Le Film de Théâtre. Paris: Ediçôes do CNRS, 1997. (Coleção Arts du spectacle/Spectacles, histoire, société).

PORTE, Michèle. Savannah Bay c'est toi. Autor e diretor: Marguerite Duras, com Madeleine Renaud, Bulle Ogier e outros. [Bry-sur-Marne], INA, cop. 1983. 69 min.

PROUST, Sophie. L'Approche Génétique du Théâtre au sein des Voies de la CRÉATION THÉÂTRALE. In: GRESSILLON, Almuth; LÉGER, Nathalie (Org.). Genesis, Paris, JeanMichel Place, n. 26, p. 165-168, 2006.

ROSTAIN, Michel. Journal des Répétitions de La Tragédie de Carmen. In: BANU, Georges (Org.). Brook. Paris: éditions du CNRS, 1985. P. 191-218. (Coleção Les Voies de la Création Théâtrale, v. XIII).

ROY, Irène. Le Théâtre Repère. Du ludique au poétique dans le théâtre de recherche. Quebec: Nuit blanche éditeur, 1993. 
SALLENAVE, Danièle. De l'Esquisse. In: Les Épreuves de l'Art. Arles: Actes Sud, 1988. P. 29-38. (Le Temps du Théâtre).

THOMASSEAU, Jean-Marie. Les Différents États du Texte Théâtral. Pratiques, Metz, CRESEF, n. 41, p. 99-121, mar. 1984. (L'Écriture Théâtrale).

THOMASSEAU, Jean-Marie. Les Textes du Spectacle ou la Toile de Pénélope. In: COUTY, Daniel; REY, Alain (Org.). Le Théâtre (1980). Paris: Larousse/VUEF, 2003. P. 91-98.

VAN HULLE, Dirk. L'Obscène et la (dé)composition Textuelle dans l'CEuvre Théâtrale de Samuel Beckett. In: GRÉSILLON, Almuth; MERVANT-ROUX, Marie-Madeleine; BUDOR, Dominique (Org.). Genèses Théâtrales. Paris: CNRS Éditions, 2010. P. 143-155.

VAN DRIE, Melissa. Quand la Radio fait du Théâtre. Le Douzième Coup de Minuit (1933). Revue de la Bibliothèque Nationale de France, Paris, n. 29, p. 50-58, jun. 2008.

VILAR, Jean. Le Théâtre, Service Public et Autres Textes. Paris: NRF, Gallimard, 1975. (Coleção Pratique du Théâtre).

Almuth Grésillon estudou literatura na Alemanha e linguística na França. É doutora na área e uma das pioneiras da Genética Teatral na França. É pesquisadora do CNRS desde 1972. É autora de diversas obras na França e no exterior.

E-mail: almuth.gresillon@ens.fr

Marie-Madeleine Mervant-Roux é pesquisadora do CNRS na área de Estudos Teatrais. Ela coordena desde 2008, com Jean-Marc Larrue, no CRIalt, em Montréal, um projeto internacional sobre O Som no Teatro (séculos XIX-XXI). É uma das pioneiras da Genética Teatral e tem diversas publicaçóes na França e no exterior.

E-mail: marie-madeleine.mervant-roux@cnrs.fr

Dominique Budor é professora na Université Paris 3 Sorbonne Nouvelle, na França. Tem diversas publicaçóes na França e no exterior.

E-mail: dominique.budor@univ-paris3.fr

Traduzido do original em francês por Weslin de Jesus Santos Castro (Aliança Francesa de Aracaju/SE), sob a supervisão de Dominique Marie Philippe Geneviève Boxus (Universidade Federal Fluminense). Revisado por Márcio Müller.

Recebido em 17 de dezembro de 2012 Aprovado em 03 de março de 2013 